\title{
Caracterização de rejeito do beneficiamento de esmeraldas visando seu aproveitamento no setor agrícola
}

\section{Emerald mining tailings characterization aiming its uses for agricultural purposes}

\author{
Lima, I.C.F.de ${ }^{1}$; Paulino, G.M. ${ }^{2 *}$; Neves, A.B.V. ${ }^{3}$; Diniz, F.F. ${ }^{4}$ \\ 1,2,3,4 Universidade do Estado de Minas Gerais, João Monlevade, MG, Brasil.
}

Gleicia.paulino@uemg.br

\begin{abstract}
RESUMO
O reaproveitamento de rejeitos da mineração é uma alternativa que pode reduzir os passivos socioambientais associados a esta atividade, pois pode contribuir para a redução dos rejeitos estocados em barragens. O objetivo do trabalho foi realizar a caracterização de rejeito esmeraldífero, obtido de uma empresa de extração de esmeraldas, localizada em Itabira/MG e verificar a possibilidade do seu aproveitamento como subproduto para o setor agrícola. Foram realizadas análises granulométrica e mineralógica por difração de raios $\mathrm{X}$ e ensaio em Microscópio Eletrônico de Varredura. Cerca de 55,68\% do rejeito foi considerado ultrafino. Foi observado alto percentual de mica-flogopita $(46,9 \%)$, seguida de anfibólio $(16,8 \%)$, cujos minerais contém magnésio $(\mathrm{Mg})$ e potássio $(\mathrm{K})$ em sua composição, os quais são elementos de interesse agronômico. Estudos que visem determinar a concentração de elementos químicos no rejeito e a sua liberação da estrutura mineral são necessários para confirmar a viabilidade de aproveitamento desse tipo de rejeito como subproduto para aplicação no setor agrícola.
\end{abstract}

Palavras-chave: Rejeito de esmeralda, Caracterização mineralógica, Reaproveitamento.

\begin{abstract}
The reuse of mining tailings is an alternative that can reduce the social and environmental liabilities associated with this activity, as it may contribute to the reduction of tailings stored in dams. The objective of this work was to characterize the emerald waste, obtained from an emerald extraction company, located in Itabira / Minas Gerais, Brazil and to verify the possibility of its use as a byproduct for the agricultural sector. Granulometric and mineralogical analyzes were performed by X-ray diffraction and assay under Scanning Electron Microscope. About 55.68\% of the tailings were considered ultrafine. A high percentage of mica flogopite (46.9\%) was observed, followed by amphibole $(16.8 \%)$, whose minerals contain magnesium $(\mathrm{Mg})$ and potassium $(\mathrm{K})$ in their composition, which are elements of agronomic interest. Studies aiming to determine the concentration of chemical elements in the tailings and their release from the mineral structure are necessary to confirm the viability of using this type of tailings as a byproduct for application in the agricultural sector.
\end{abstract}

Keywords: Emeraldtailings, Mineralogical characterization, Reuse. 


\section{INTRODUÇÃO}

A mineração é de fundamental importância para vários segmentos da economia, levando-se em consideração dos recursos extraídos do subsolo. E não menos importante, o manejo dos rejeitos de mineração merece enfoque especial, pois podem causar impactos ambientais que, quando não são detectados e corrigidos, se transformam num passivo ambiental, o que tem acontecido com frequência no Brasil, conforme estudos de Paiva (2006) e Barreto (2001).

O rejeito da mineração é proveniente da etapa de beneficiamento físico e em algumas vezes, de beneficiamento químico do minério de interesse. Porém, é importante destacar que o aumento da quantidade de rejeito provenientes da explotação do minério, a preocupação com os impactos ambientais se elevou, demandando o desenvolvimento de uma atividade mineraria mais sustentável, de modo a reduzir ou até mesmo eliminar a geração de resíduos pela empresa. Com a destinação e aproveitamento de resíduos de mineração, a empresa ao invés de desembolsar recursos financeiros para dispor o rejeito no ambiente, ela poderá fazer um investimento para que esse rejeito seja utilizado, trazendo benefícios de ordem econômica, social e ambiental. De acordo com Amorim (2010), o grande volume de resíduos gerados pela mineração e a dificuldade no seu armazenamento tem motivado pesquisas voltadas para a reciclagem dos materiais resultantes dos processos industriais e de beneficiamento.

Existe uma tendência e necessidade de aproveitamento de resíduos, para resolver ou reduzir impactos ambientais. Este aproveitamento pode levar a geração de novos produtos para atender as demandas de vários segmentos, como por exemplos, o setor da construção civil, com a produção de concreto contendo o resíduo de mineração como componente, e o setor agropecuário, através do uso de resíduos da mineração para a produção de corretivos e fertilizantes de solo. Dentro este contexto, é possível pelo menos minimizar problemas ambientais, com vantagens econômicas e socioambientais para diferentes tipos de empreendimentos.

Segundo Silva et. al. (2008), a necessidade de obtenção de fertilizantes alternativos no Brasil tem se tornado mais evidente nos últimos anos. Além disso, cada vez mais a agricultura brasileira tem buscado novos insumos e matérias-primas para garantir a sustentabilidade e soberania do setor agrícola do país. Dentre esses insumos 
vem aumentando a busca por fertilizantes adequados para os mais diversos sistemas de produção, conforme Gardinet al.(2011).

Rejeitos provenientes da mineração contêm minerais de ordem primária e secundária, além de elementos químicos em sua composição, que podem ser empregados no setor agrícola. Insumos minerais utilizados para a fabricação de fertilizantes e corretivos do solo são incluídos aos recursos não renováveis, assim a realização de pesquisas sobre fontes alternativas de novos produtos agrícolas vem sendo cada vez mais necessária e importante, pois pode contribuir de forma significativa para a obtenção de insumos mais baratos, acessíveis e eficientes para a recuperação ou manutenção da fertilidade do solo.

O presente trabalho tem como objetivo geral realizar a caracterização física e mineralógica do rejeito proveniente do beneficiamento da lavra de esmeraldas, de uma mineradora localizada em Itabira-MG, e verificar a possibilidade do seu aproveitamento na geração de subproduto com aplicação no setor agrícola.

\section{MATERIAIS E MÉTODOS}

\subsection{Amostragem}

O rejeito esmeraldífero foi proveniente da mineração do minério de berilo (variação esmeralda), em uma mina de esmeraldas, localizada no município de Itabira, Minas Gerais. Dez amostras simples foram coletadas na pilha de rejeito, ainda úmido, imediatamente após a ciclonagem, que é última etapa processo de beneficiamento do minério berilo (variação esmeralda). A coleta foi realizada em pontos diversos, no pé da pilha, no meio e parte superior, de forma a garantir a representatividade. Posteriormente, as amostras foram encaminhadas ao Laboratório de Tratamento de Minérios da UEMGUnidade João Monlevade.

\subsection{Secagem e homogeneização}

As amostras foram espalhadas numa superfície para secagem ao natural, após foi realizada a pesagem, constatando que o material amostrado totalizava $40 \mathrm{~kg}$. Em seguida foi feita a homogeneização com auxílio de uma pá, formando uma amostra composta (Figura 1). 
Figura 1 - Homogeneização da amostra de rejeito esmeraldífero

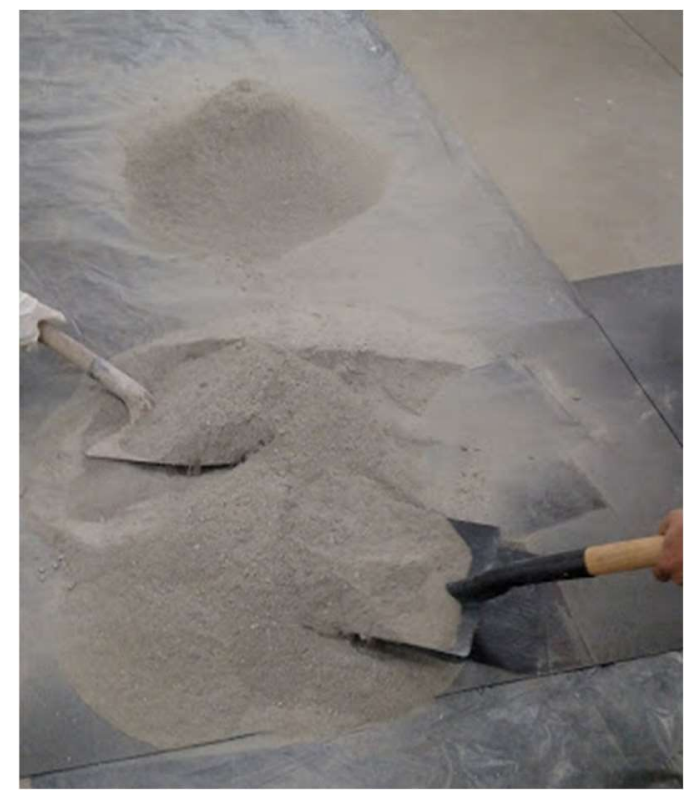

Fonte: Arquivo pessoal, 2018.

\subsection{Quarteamento}

Depois de ter realizado a homogeneização do rejeito, foi feito o quarteamento por pilha cônica utilizando a cruzeta, até reduzir a amostra para $5 \mathrm{~kg}$ (Figura 2). Em seguida, o método utilizado passou a ser com o auxílio do quarteador de rifles/Jones, reduzindo o material em duas alíquotas de $600 \mathrm{~g}$ cada. Uma dessas duas amostras foi arquivada como amostra reserva e a outra foi destinada para realização das análises.

Figura 2 - Quarteamento da amostra de rejeito esmeraldífero

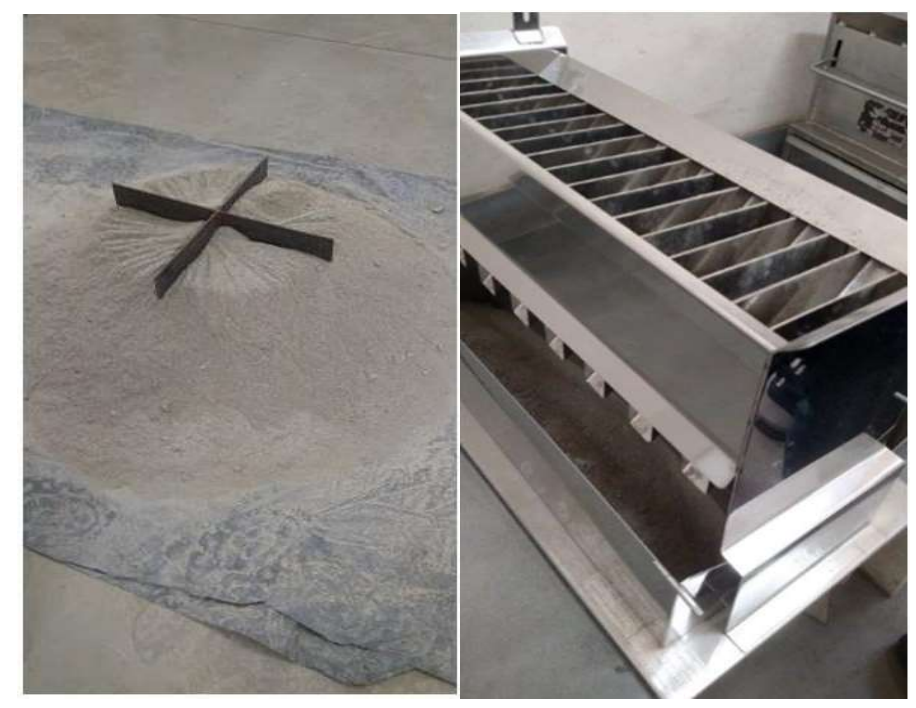

Fonte: Arquivo pessoal, 2018. 


\subsection{Análise da distribuição granulométrica}

Para a análise da distribuição granulométrica foi utilizada a peneira vibratória durante 15 minutos. Este ensaio tem como objetivo classificar as partículas em duas ou mais frações, com partículas de tamanhos distintos.

Foi realizado o peneiramento a seco, em peneirador vibratório suspenso, tendo sido classificada oito peneiras da série Tyler para tal procedimento, com aberturas de $3,35 \mathrm{~mm}(6 \#) ; 0,085 \mathrm{~mm}(20 \#) ; 0,5$ (35\#);0,250mm (60\#);0,149mm (100\#);0,106mm $(140 \#) ; 0,075 \mathrm{~mm}(200 \#)$ e $0,038 \mathrm{~mm}(400 \#)$. A figura 3 ilustra a etapa de peneiramento realizada no Laboratório de Tratamento de Minérios da UEMG-Unidade João Monlevade.

Figura 3 - Peneirador vibratório suspenso para determinação da análise granulométrica do rejeito esmeraldífero

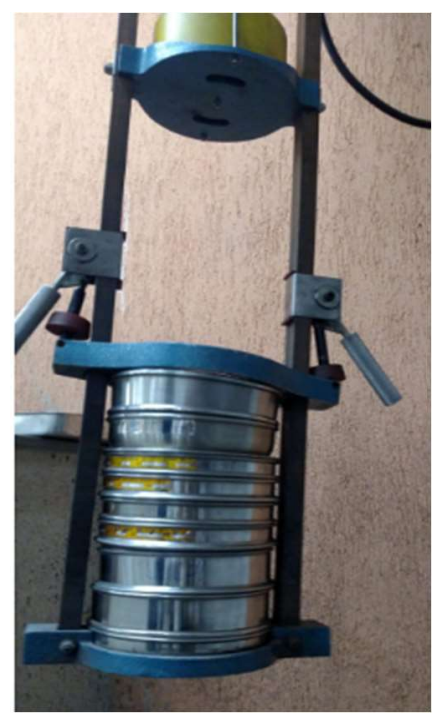

Fonte: Arquivo pessoal, 2018.

\subsection{Análise mineralógica}

Uma fração da amostra composta de rejeito foi utilizada para a realização de análise em Microscópio Eletrônico de Varredura (MEV), para obtenção de imagens da estrutura superficial e características da amostra. Esta análise também foi utilizada da UEMG-unidade João Monlevade.

Outra fração da amostra composta foi enviada ao Laboratório do Departamento de Engenharia de Minas da Universidade Federal de Minas Gerais (UFMG) para 
realização da análise mineralógica por Difração de Raios X (DRX), visando a identificação e quantificação das fases minerais presentes no rejeito.

\section{RESULTADOS E DISCUSSÃO}

\subsection{Análise Granulométrica}

O ensaio de peneiramento se faz importante para conhecer as características das partículas minerais em determinadas faixas de tamanho. Além de que, evidencia que a amostra se encontra na faixa adequada para ser analisada mineralogicamente pelos métodos pré-estabelecidos.

Após a amostra passar pelas oito peneiras da série Tyler, durante 15 minutos no peneirador vibratório, foram obtido os seguintes dados de distribuição granulométrica dispostos na tabela 1.

Tabela 1 - Distribuição granulométrica do rejeito esmeraldífero

\begin{tabular}{cccccccc}
\hline \begin{tabular}{c} 
Faixa \\
\multicolumn{2}{c}{ granulométrica }
\end{tabular} & \multicolumn{7}{c}{ Alimentação } \\
\hline $\begin{array}{c}\text { Malha } \\
(\#)\end{array}$ & $\begin{array}{c}\text { Abertura } \\
(\mathbf{m m})\end{array}$ & $\begin{array}{c}\text { Massa } \\
\mathbf{1}(\mathbf{g})\end{array}$ & $\begin{array}{c}\text { Massa } \\
\mathbf{2 ( g )}\end{array}$ & $\begin{array}{c}\text { Massa } \\
\text { média (g) }\end{array}$ & $\begin{array}{c}\text { \% } \\
\text { Retido }\end{array}$ & $\begin{array}{c}\text { \% Retido } \\
\text { acumulado }\end{array}$ & $\begin{array}{c}\text { \% } \\
\text { Passante }\end{array}$ \\
\hline 6 & 3,35 & 14,40 & 14,10 & 14,25 & 2,25 & 2,25 & 97,75 \\
\hline 20 & 0,85 & 62,20 & 59,40 & 60,80 & 9,59 & 11,83 & 88,17 \\
\hline 35 & 0,5 & 45,50 & 43,00 & 44,25 & 6,98 & 18,81 & 81,19 \\
\hline 60 & 0,25 & 87,00 & 82,40 & 84,70 & 13,36 & 32,17 & 67,83 \\
\hline 100 & 0,15 & 78,40 & 75,70 & 77,05 & 12,15 & 44,32 & 55,68 \\
\hline 140 & 0,106 & 86,70 & 77,50 & 82,10 & 12,95 & 57,26 & 42,74 \\
\hline 200 & 0,075 & 92,50 & 119,80 & 106,15 & 16,74 & 74,00 & 26,00 \\
\hline 400 & 0,038 & 132,80 & 102,50 & 117,65 & 18,55 & 92,55 & 7,45 \\
\hline$<400$ & 0,038 & 51,70 & 42,80 & 47,25 & 7,45 & 100,00 & - \\
\hline
\end{tabular}

Fonte: Arquivo pessoal, 2018.

Analisando os dados apresentados na tabela 1, plotou-se o gráfico 1, em escala logarítmica no eixo das abscissas, no intuito de representar o passante acumulado em função da abertura das peneiras. Dessa forma, com base nos dados apresentados, podese observar que 55,68\% do rejeito é considerado ultrafino, ou seja, com partículas menores que $0,15 \mathrm{~mm}$. 
Gráfico 1 - Curva de distribuição granulométrica do rejeito esmeraldífero

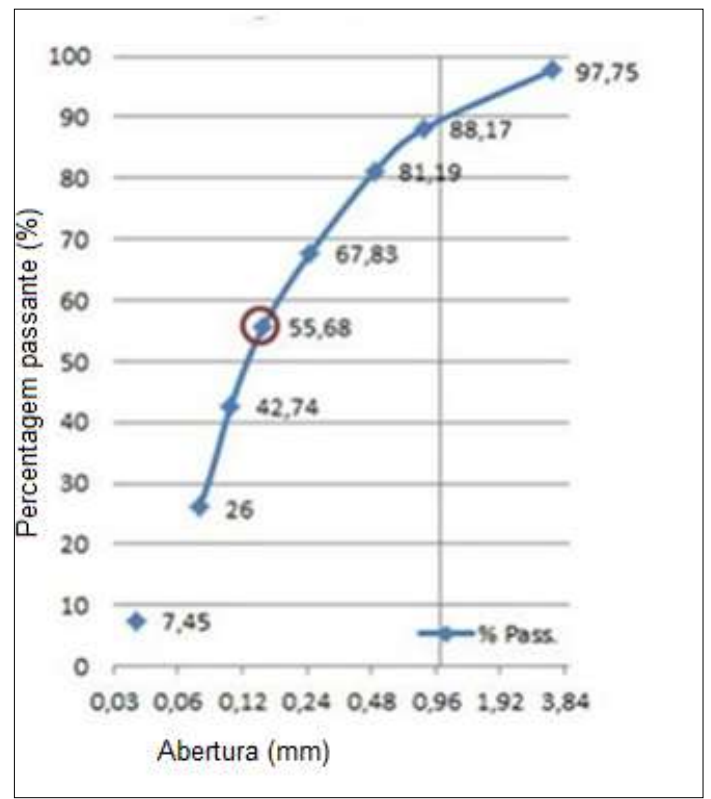

Fonte: Arquivo pessoal, 2018

\subsection{Análise Mineralógica}

$\mathrm{Na}$ análise mineralógica há o ensaio qualitativo e quantitativo da amostra de rejeito. A análise pelo Microscópio Eletrônico de Varredura (MEV) tem a finalidade de verificar a morfologia das partículas e observar a composição elementar. A figura 4 mostra imagens coletadas pelo MEV, onde é possível obter informações estruturais como a estrutura lamelar da flogopita.

Figura 4 - Imagens da amostra de rejeito esmeraldífero em MEV

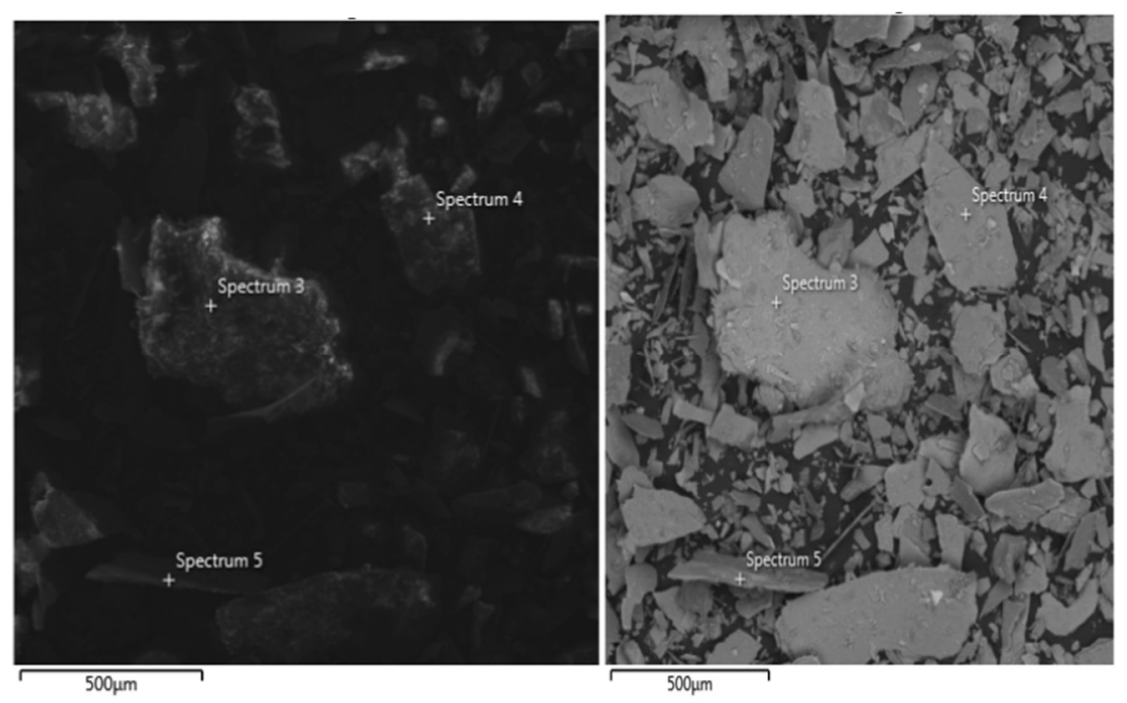

Fonte: Arquivo pessoal, 2018. 
As figuras 5, 6 e 7 obtidas pelo MEV mostram os resultados da análise quantitativa dos elementos constituintes do rejeito. Observa-se a presença dos elementos Oxigênio, Silício, Magnésio, Ferro, Potássio e Alumínio. Observa-se que o oxigênio é o elemento mais abundante, seguido do silício. Porém o elemento mais interessante, nesse caso, é o magnésio, que é o terceiro componente dos elementos que o rejeito esmeraldífero contém que aprece nos espectros 3, 45. O potássio aparece apenas no espectro 4 (Figura 6).

Figura 5 - Análise quantitativa dos elementos constituintes de rejeito esmeraldífero Spectrum 3

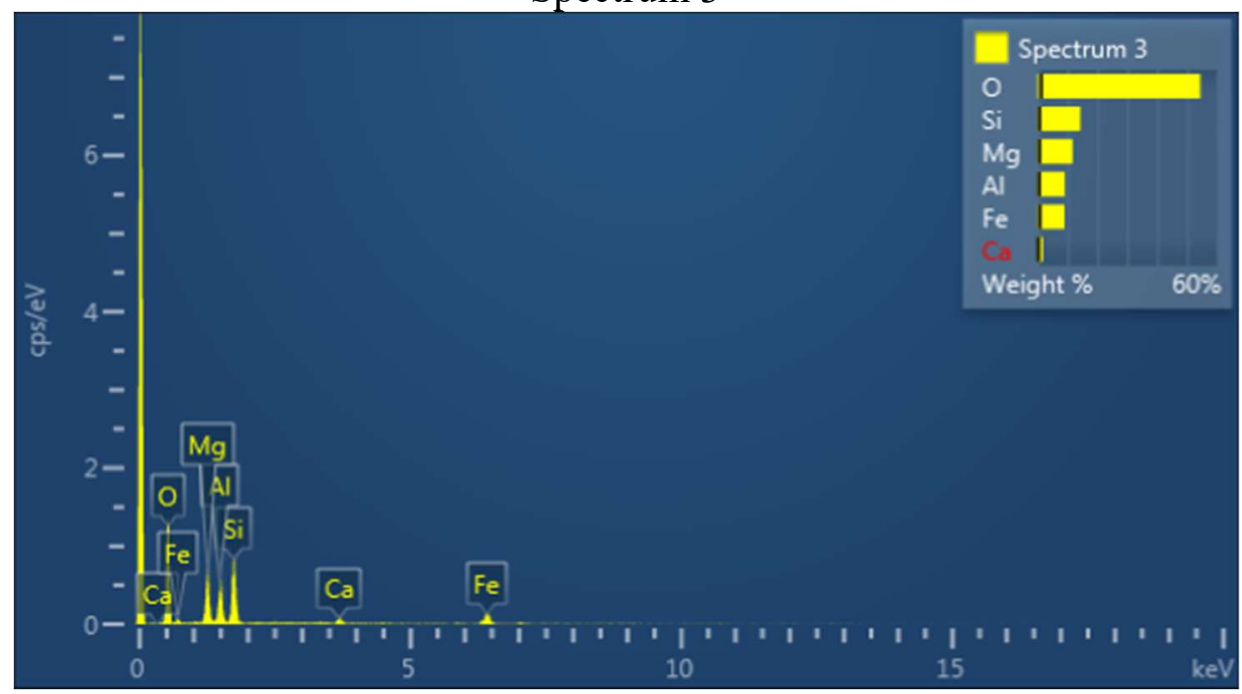

Fonte: Arquivo pessoal, 2018.

Figura 6 - Análise quantitativa dos elementos constituintes de rejeito esmeraldífero Spectrum 4

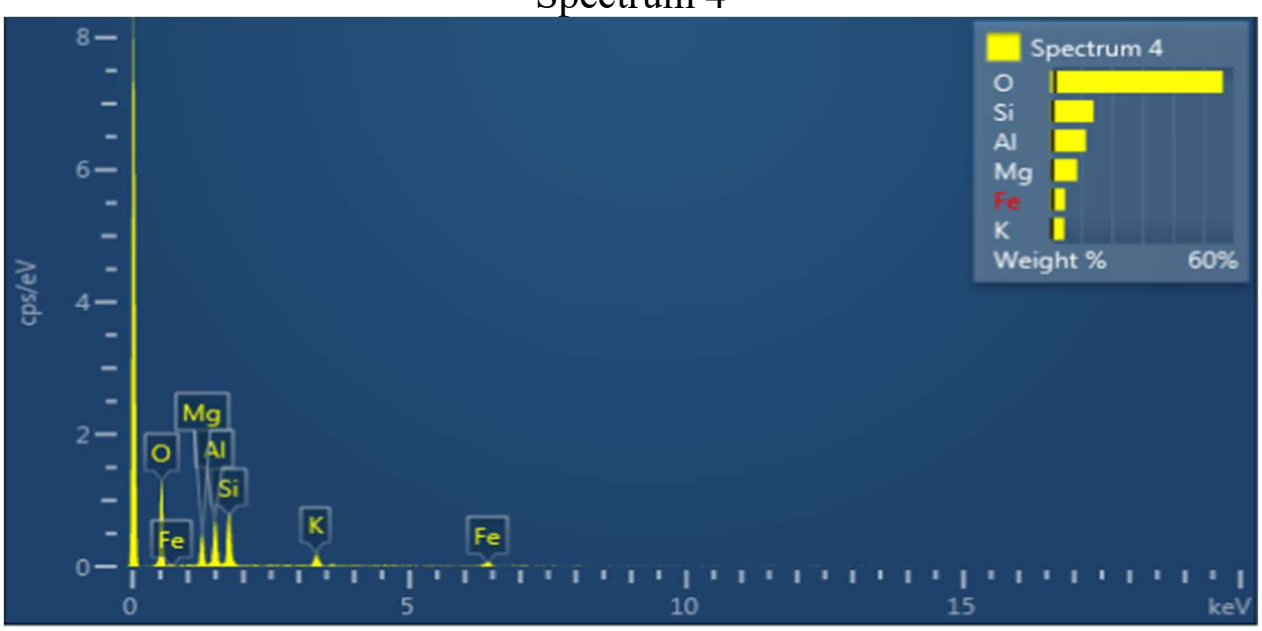

Fonte: Arquivo pessoal, 2018. 
Figura 7 - Análise quantitativa dos elementos constituintes de rejeito esmeraldífero Spectrum 5

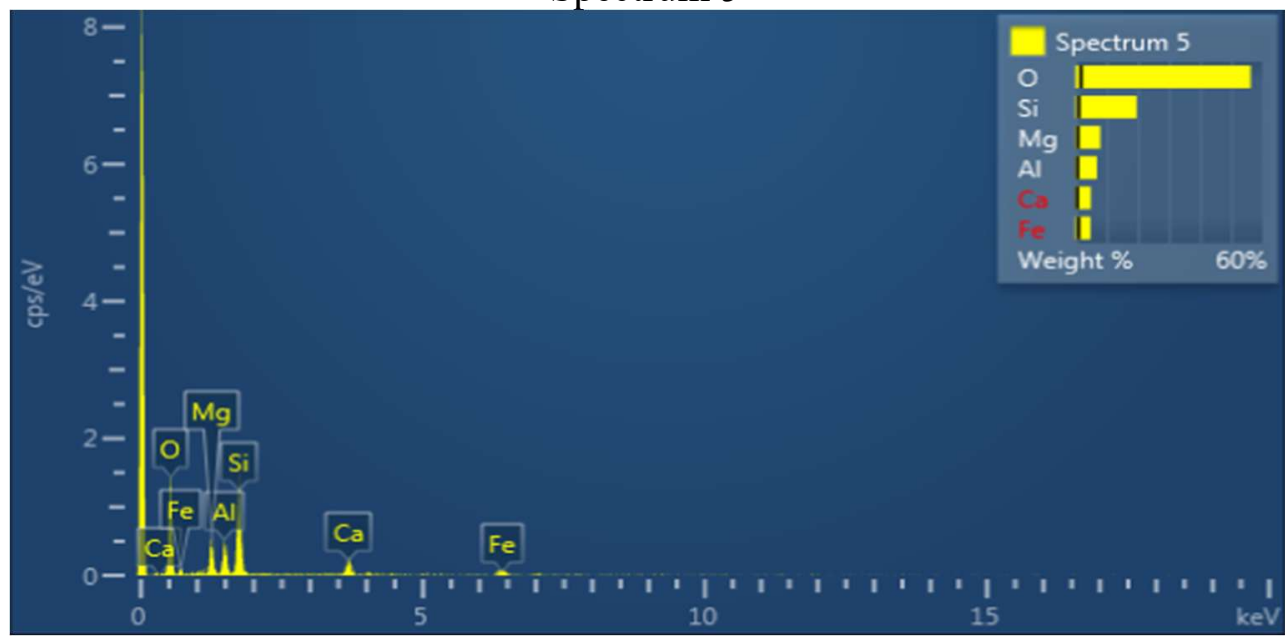

Fonte: Arquivo pessoal, 2018.

Pela análise mineralógica quantitativa realizada pela Difração de Raios-X (DRX) foi identificada e quantificada as espécies minerais presentes no rejeito. A tabela 2 mostra a em percentagem das fases minerais presentes na amostra de rejeito esmeraldífero, obtidos pelo refinamento High Score.

Tabela 2 - Percentagem, em massa, das fases minerais identificadas no rejeito esmeraldífero

\begin{tabular}{ccccccc}
\hline Amostra & $\begin{array}{c}\text { Mica } \\
\text { (flogopita) }\end{array}$ & Quartzo & $\begin{array}{c}\text { Anfibólio } \\
\text { (actinolita) }\end{array}$ & Talco & Caulinita & Vermiculita \\
\cline { 2 - 7 } & & \multicolumn{5}{c}{$\%$} \\
\hline $\begin{array}{c}\text { Rejeito } \\
\text { esmeraldífero }\end{array}$ & 46,90 & 30,60 & 16,80 & 3,40 & 2,20 & 0,10 \\
\hline
\end{tabular}

Fonte: Arquivo pessoal, 2018.

Pode-se observar na tabela 2 um alto percentual de mica - flogopita (46,9\%), seguida do anfibólio (16,8\%), que são minerais que contém em sua composição magnésio $(\mathrm{Mg})$ e potássio $(\mathrm{K})$, que são elementos de interesse agronômico. Outros dois minerais observados no rejeito que contém em sua composição elementos de interesse agronômico encontram-se em percentuais muito baixo, como o talco $(3,4 \%)$ e a vermiculita (2,2\%). Os demais minerais observados não são de interesse agronômico, como o quartzo e a caulinita.

O difratograma obtido para a amostra esmeraldífera é apresentado na figura 8 e mostra as principais fases minerais presentes na amostra do rejeito esmeraldífero. 
Figura 8 - Difratograma da amostra de rejeito esmeraldífero com as principais fases minerais presentes

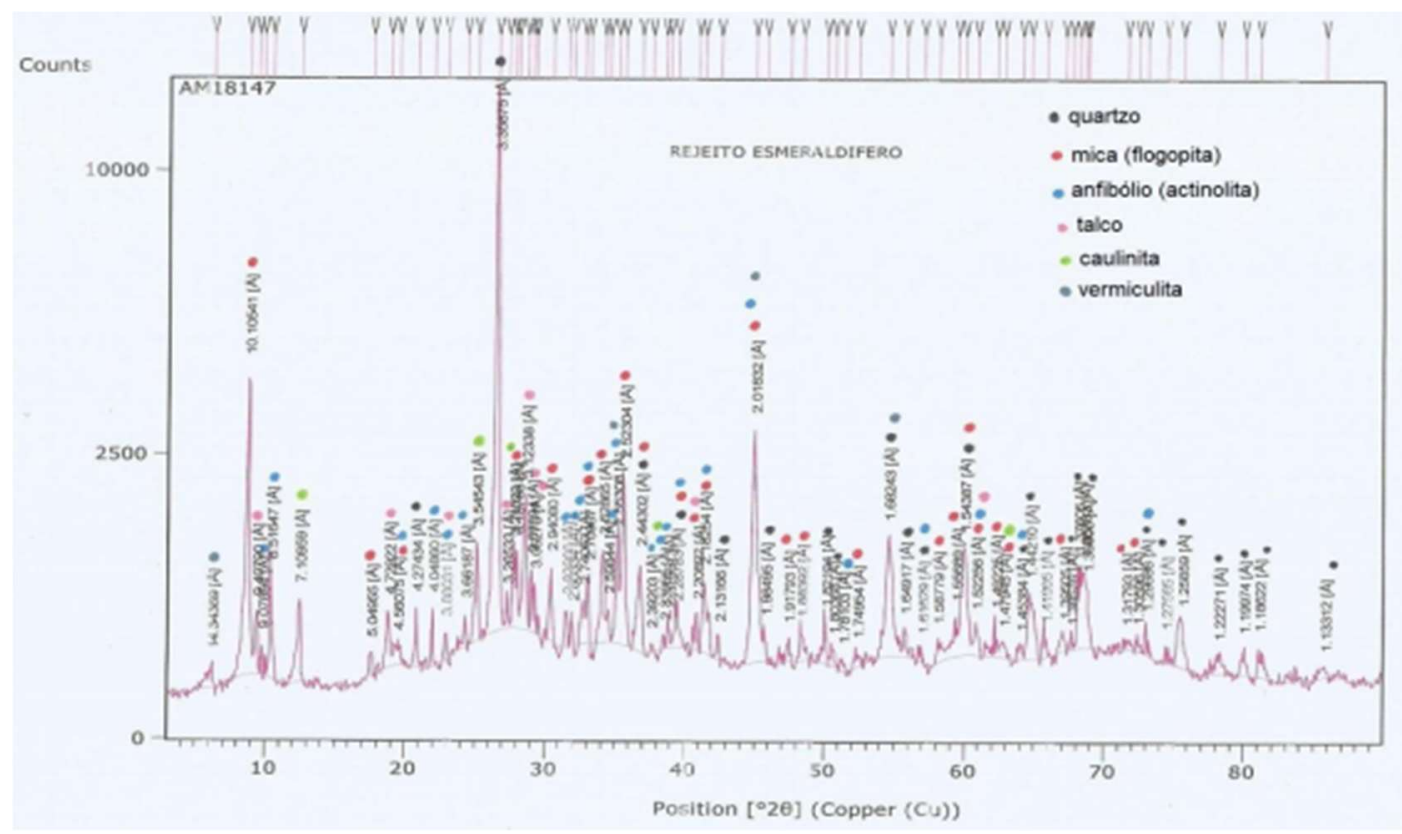

Fonte: Arquivo pessoal, 2018

Devido ao fato do rejeito esmeraldífero apresentar alta porcentagem de mica, do tipo flogopita $(46,9 \%)$ e anfibólio (16,8\%), principais mineral-minério que contém potássio e magnésio (Tabela 2), mostra que o rejeito talvez possa ser aproveitado para uso no setor agrícola como fertilizante químico.

Minerais do grupo das micas como a biotita ou as vermiculitas, que constituem um grupo de minerais micáceos, argilosos, de composição química muito variada, derivados habitualmente da alteração de micas como a biotita e a flogopita são fontes potenciais do íon potássio (NASCIMENTO e LOUREIRO, 2009).

Estudos também mostram que algumas rochas contendo biotita ou flogopita têm potencial para uso na agricultura, constatando que a flogopita possui características que possibilitam seu uso in natura, como fonte de potássio (FILHO et al., 2006 apud SILVA et al., 2008) e o anfibólio como fonte de magnésio.

Contudo, Silva (2008) relata que a flogopita quando tratada com ácido nítrico, resulta em uma maior quantidade de potássio livre. Especificamente no caso da mica flogopita, o cátion de compensação predominante é o potássio, e a forma como o íon potássio está preso à estrutura cristalina da flogopita dificulta a sua remoção e liberação 
para o meio. Levando em consideração o poder reativo do mineral para a liberação de elementos, de acordo com Silva et al. (2008), são necessários a realização de estudos interdisciplinares, de análise de custo de produção. Também, conforme Silva et al. (2010), é importante considerar o tipo de cultivo e os fatores ambientais, dentre outros, para definir a viabilidade de aplicação de determinado mineral como fertilizante, como o caso da flogopita.

Dentre deste contexto, para verificar se o rejeito de esmeraldífero realmente apresenta viabilidade de aproveitamento como fertilizante, análises químicas para verificar a concentração de elementos químicos bem como sua liberação do complexo mineral deverão ser realizadas para confirmar a viabilidade ou não do aproveitamento do rejeito esmeraldífero no setor agrícola.

\section{CONCLUSÃO}

Pela caracterização físico-química e mineralógica do rejeito esmeraldífero é possível concluir que este resíduo apresenta fases minerais que contêm elementos de interesse agronômico para fins de uso como fertilizante de solo.

Mica flogopita e anfibólio foram as fases minerais de interesse agronômico presentes no rejeito em maiores percentuais, 46,9 e $16,8 \%$, respectivamente;

Associando as fases minerais presentes e os elementos químicos constituintes das mesmas, pode-se inferir que o rejeito pode ser fonte de $\mathrm{Mg}$ e $\mathrm{K}$, elementos importantes como fertilizantes.

Análises sobre a concentração dos elementos químicos no rejeito, bem como sua liberação no meio são importantes e fundamentais para confirmar o potencial de uso deste resíduo no setor agrícola, como componente de fertilizante mineral.

\section{AGRADECIMENTOS}

Ao Departamento de Engenharia de Minas da UFMG pela contribuição na realização da análise mineralógica.

À UEMG e ao Programa Institucional de Apoio à Pesquisa pelo apoio logístico e concessão da bolsa de iniciação científica durante a realização da pesquisa.

À Mineradora de Itabira/MG, pela doação de amostras de pegmatitos. 


\section{REFERÊNCIAS}

AMORIM, T. R.Q; AMORIM, E. F. Utilização de pó de pedra gerado pelo beneficiamento de agregados como material de fíler em obras viárias. In: COBRAMSEG. Engenharia Geotécnica para o desenvolvimento, inovação e sustentabilidade. Gramado-RS: ABMS, 2010. 8p.

BARRETO, M. L. Mineração e desenvolvimento sustentável: desafios para o Brasil. Rio de Janeiro. CETEM/MCT - Centro de Tecnologia Mineral, 2001, 215 p.

GARDIN, J.P.P.; DOUMER, M.E.; MESSIAS, R.S.; SOUZA, E.L.; FERNANDES, A.; ROZA-GOMES, M.F. Produtividade da cultura do milho e atividade de enzimas do metabolismo dos carboidratos com fertilizantes foliares contendo água de xisto.Evidência, v.11, n.2, 2011, p. 83-90.

NASCIMENTO, M., Loureiro, F.E.L., Fertilizantes e sustentabilidade: o potássio na agricultura brasileira, fontes e rotas alternativas. Séries Estudos e Documentos, v.61, Rio de Janeiro, Brasil: CETEM/MCT, 2009.

PAIVA, C. T. Proposta de metodologia para análise de passivos ambientais da atividade minerária. Ministério de Minas e Energia - MME. 2006. Disponível em: $<$ http://www.mma.gov.br/port/conama/reuniao/dir934/RelatConsultoriaApresentaoMM E_PassivosAmbientais.pdf $>$. Acesso em: 05 out. 2018.

SILVA, D. de S.; FRANÇA, S.C.A.; SILVA, A.de A.S Beneficiamento do flogopitito para uso como fertilizante de liberação lenta. Anais da XVI Jornada de Iniciação Científica. 2008, 7p. Rio de Janeiro: CETEM/MCT, 2008.

SILVA, A. de A.S.; FRANÇA, S.C.A.; RONCONI, C.M; SAMPAIO, J.A; LUZ, A.B. da; SILVA, D. de S. Flogopitito da Bahia como fonte de potássio para a agricultura brasileira. In: Anais do II Simpósio de Minerais Industriais do Nordeste. Parte III Agrominerais. Campina Grande: CETEM/UFPE, 2010. p.115-123. 